\title{
O DESAFIO DE INSERÇÃO DAS TECNOLOGIAS DIGITAIS NA ESCOLA BÁSICA CONTEMPORÂNEA
}

\author{
FRANCO, Vera Nácia Duarte ${ }^{1}$ \\ PORTO, Maria Beatriz Dias da Silva² \\ ALMEIDA, Lidiane Aparecida ${ }^{3}$
}

\section{RESUMO}

Este artigo apresenta uma reflexão teórica sobre a importância de compreender como os processos e as práticas educacionais interferem na qualidade da educação. Parte-se do pressuposto de que a boa formação do docente é essencial para que se estabeleça uma prática reflexiva, consciente e transformadora e de que a utilização das Novas Tecnologias da Informação e da Comunicação (NTIC) pode potencializar e tornar o processo de ensino e aprendizagem mais significativo. Embora a inserção das TIC configure um desafio na Educação, a pesquisa realizada para a elaboração deste trabalho mostrou, entre outras coisas, que é necessária uma mudança de paradigma para a construção de uma nova escola. Tal mudança depende de investimentos na formação inicial e continuada dos professores para utilizar pedagogicamente as Tecnologias da Informação e da Comunicação de forma significativa.

PalaVRas-ChaVe: Tecnologia de Informação e Comunicação - Formação do professor Aprendizagem Significativa.

\section{ABSTRACT}

This paper presents a theoretical reflection on the importance of understanding how processes and educational practices affect the quality of education. We start from the assumption that proper training of teachers is essential to establish a reflexive, conscious and transforming practice and also that the use of New Technologies of Information and Communication (NTIC) can improve the process of learning and make it more meaningful. Although the inclusion of NTIC sets a challenge upon education, research we carried out as a preparation for this study showed, among other things, that we need a paradigm shift on the construction of a new school. This change depends on investments upon initial and continued training of teachers in using NTIC in a pedagogical and significant way.

KeYwORDS: Technologies of Information and Communication - Teacher training - Meaningful learning.

\footnotetext{
${ }^{1}$ Mestre em Ensino de Educação Básica (PPGEB/CAp-UERJ). Email: naciaduarte@gmail.com

${ }^{2}$ Professora Adjunta da Universidade do Estado do Rio de Janeiro. Instituto de Aplicação Fernando Rodrigues da Silveira (CAp-UERJ). E-mail: beatrizrj@mail.com

${ }^{3}$ Professora Adjunta da Universidade do Estado do Rio de Janeiro. Instituto de Aplicação Fernando Rodrigues da Silveira (CAp-UERJ). E-mail: lidialmeida0909@gmail.com
} 


\section{INTRODUÇÃO}

Os países em desenvolvimento enfrentam o desafio de modernizar seus sistemas educativos e superar o modelo de escola que conhecemos atualmente, retrato da sociedade industrial do século XIX, com um currículo organizado para satisfazer as necessidades de uma sociedade industrial, tendo o professor como centro do processo educacional e o aluno, receptor passivo. Libâneo (2012, p. 115) afirma que esta escola, que antes preparava os sujeitos para executar tarefas repetidas, continua seguindo um modelo de exploração que exige cada vez mais e "requer um novo trabalhador, com habilidades de comunicação, abstração, visão de conjunto, integração e flexibilidade". Essa postura incentiva a competitividade e faz com que a escola viva sob o espírito direto dos setores produtivos.

Segundo a Constituição de 1988, também chamada de Constituição Cidadã, a escola de hoje tem ainda o ideário de querer preparar o aluno para a vida, respeitando sua individualidade, formando-o para ser um cidadão crítico e atuante, uma vez que a Educação escolar teria por finalidades o "pleno desenvolvimento da pessoa" e o "preparo para o exercício da cidadania" - vide artigos 205 a 214 da Constituição Federal (BRASIL, Constituição, 1988).

Por isso mesmo, Sacristán (2000, p. 29) chamou a atenção para a coexistência atual de duas escolas, ora tradicional e conservadora, ora revolucionária e progressista: "as ideias pedagógicas mais aceitáveis e potencialmente renovadoras podem coexistir, e de fato coexistem, com uma prática escolar obsoleta". Diante dessa coexistência, há de se perceber que a escola contemporânea enfrenta grandes desafios, dentre os quais a inclusão das TIC de forma significativa, respondendo à demanda de acesso universal à Educação básica, sem levar em conta o tamanho dos municípios, sua situação geográfica e con- dições econômicas, sendo obrigados a oferecer uma educação que atenda também as necessidades da comunidade, considerando inclusive sua diversidade cultural (TEDESCO, 2004).

Portanto, é fundamental conhecer os processos e as práticas históricas de educação para ampliarmos nossa compreensão das maneiras como, em tempos e espaços distintos, as pessoas organizaram e organizam seus modos de aprender e de transmitir seus fazeres e saberes (VEIGA, 2007). Deve ser esclarecido que a Educação brasileira, e, mais especificamente, a Educação Pública, tem um histórico de crises, muitas vezes políticas: muitos desafios que não foram superados ao longo de séculos se acumularam, o que gerou novos problemas. Precisamos indagar sobre o acúmulo das experiências do passado, para poder refletir as experiências do presente e, assim, apresentar soluções mais promissoras para a superação dos problemas atuais.

A escola, como instituição formadora de cidadãos, palco dos acontecimentos sociais, políticos, econômicos e culturais, tem de refletir sobre seu papel no mundo atual. Afinal, como lembram Marchesi \& Martín (2003), a influência da escola na sociedade e o reflexo desta na escola estão intrinsecamente relacionados, pois "as ideologias que operam no mundo educativo não estão desvinculadas das diferentes concepções que existem sobre a sociedade"; ao contrário, todos os esforços têm a finalidade de tornar a Educação mais qualitativa e a "qualidade do ensino deve levar em conta as finalidades gerais da Educação, o contexto em que se produz e o conjunto de seus processos" (MARCHESI \& MARTÍN, 2003, p. 22).

Desse modo, se a escola de qualidade é aquela que estimula o desenvolvimento cognitivo, social e afetivo do aluno, para que ele se torne um profissional competente e um cidadão atuante e consciente, devem-se levar em conta as dife- 
renças individuais e as características do meio social onde ele vive, porque é desse cenário que veremos nascer um novo modelo de escola Pública no século XXI, qual seja aquele de uma escola que apoia a escolarização de alunos que se encontram socialmente e culturalmente desfavorecidos e, segundo defendemos, as novas tecnologias da informação e da comunicação podem colaborar para tal avanço.

As Novas Tecnologias da Informação e da Comunicação (NTIC) apresentam um relevante papel para a renovação dos sistemas educativos. Para cumprir este desafio não basta equipar as escolas com computadores, vemos também que há necessidade de um investimento em pesquisa e em experimentos planejados, para pôr em prática ideias que geram novas práticas e teorias (TEDESCO, 2004).

Desde a década de 1980, observase que os educadores mais arrojados consideram a inclusão das tecnologias na escola algo inevitável e essencial para mudar o paradigma tradicional e, então, incorporar novas teorias à prática pedagógica. Todavia, essa nova concepção de ensino e aprendizagem, embora tivesse um grande potencial educativo, por si só não seria suficiente para resolver os problemas educacionais que foram acumulados ao longo de décadas, ou, mais propriamente no caso brasileiro, ao longo de séculos. Logo, é escusado apontar que as tecnologias são importantes, mas não resolvem as questões de fundo, como o grande desafio de ensinar e aprender na transição do modelo de gestão industrial para o da informação e do conhecimento (MORAN, 2012).

Em vista disso, introduzir as diferentes Tecnologias da Informação e da Comunicação no processo de ensino e aprendizagem não só implica em mudanças administrativas e de gestão: é necessário, também, que haja uma participação ativa de todo o corpo docente, que deve contribuir pedagogicamente e mudar valores e comportamentos.
Por esse motivo, quanto mais cedo essas interações e intervenções acontecerem, maiores serão as possibilidades de potencializar o aprendizado através das TIC. Por isso, a utilização das novas ferramentas, em especial do computador, em sala de aula, promove mudanças substanciais na relação professor-aluno, bem como alterações, para melhor, na organização do pensamento humano. Ao dominar e proporcionar os novos meios, o professor reinventa a sua prática dia após dia e assume uma nova atitude diante do conhecimento e da aprendizagem; deixa de ser o detentor do saber para se tornar um facilitador e mediador do processo de ensino e aprendizagem. Nesta mudança é necessário cuidado, porque a evolução tecnológica exige mais criatividade e centra a mediação na figura do professor que tem a possibilidade de desenvolver o senso crítico dos estudantes, auxiliando-os a selecionar as informações, construindo novos conhecimentos de forma significativa.

Os computadores possibilitam representar e testar ideias ou hipóteses, que levam à criação de um mundo abstrato e simbólico, ao mesmo tempo em que introduz diferentes formas de atuação e de interação entre as pessoas. Essas novas relações, além de envolverem a racionalidade técnico-operatória e lógico-formal, ampliam a compreensão sobre aspectos sócio-afetivos [sic] e tornam evidentes fatores pedagógicos, psicológicos, sociológicos e epistemológicos (ALMEIDA, 2000, p. 12).

Então, um dos maiores desafios da escola é incorporar qualitativamente as Tecnologias da Informação e da Comunicação, não para que a máquina, por si só, mude a escola, mas para que a escola se aproprie da tecnologia e transforme o seu currículo, sua abordagem e, claro, mude a relação com os alunos e a relação deles 
com o aprendizado. Segundo Lima Júnior (2005, p. 15), a tecnologia é:

[...] um processo criativo através do qual o ser humano utiliza-se de recursos materiais e imateriais, ou os cria a partir do que está disponível na natureza e no seu contexto vivencial, a fim de encontrar respostas para os problemas de seu contexto, superando-os.

E essa transformação passa pela formação do professor e haverá de contribuir para "exercitar uma adequada pedagogia dos meios, uma pedagogia para a modernidade" (ALMEIDA, 2000, p. 11), o que, ainda segundo a autora, "é pensar no amanhã, numa perspectiva moderna e própria de desenvolvimento". No entanto, para que essas mudanças aconteçam, é necessária uma gestão comprometida com uma Educação de qualidade.

Segundo Gadotti (2000, p. 250), essa perspectiva na sociedade da informação demanda a participação ativa de todos que participam desse processo no qual:

\begin{abstract}
a escola deve servir de bússola para navegar nesse mar do conhecimento, superando a visão utilitarista de oferecer informações "úteis" à competitividade, para obter resultados. Deve oferecer uma formação geral na direção de uma educação integral.
\end{abstract}

\section{OS DESAFIOS EdUCACIONAIS À FORMAÇÃO DO PROFESSOR}

A formação docente continuada pode favorecer mudanças significativas na escola, mas o desenvolvimento dos profissionais da Educação precisa ser somado a uma gestão competente que conceba os professores como seres singulares e seja capaz de articular cada integrante do processo, seja ele educador, seja educando. É importante que a gestão se faça sensível para perceber as dificuldades de cada ator do processo de ensino e aprendizagem, que observe as suas competências e que esteja preparada para auxiliar no que for necessário, principalmente porque, segundo Thurler (2008, p. 139), "a dimensão pessoal é geralmente mais importante do que a tecnologia"; afinal de contas, a ausência de uma relação de respeito mútuo e compartilhamento de responsabilidades torna impossível o bom uso das tecnologias na Educação.

Além da responsabilidade compartilhada, deve haver planejamento e integração das disciplinas em função de objetivos comuns, mesmo porque os novos padrões de gerenciamento escolar apontam para um tratamento muito cuidadoso, enfim, para um novo modelo de profissionalismo, que deve ser:

caracterizado pela evolução dos valores e práticas dos professores em favor de uma relação mais próxima entre desenvolvimento profissional e desenvolvimento institucional. As transformações mais significativas dão lugar à cooperação; as relações hierárquicas são substituídas pelo trabalho em equipe; a supervisão evolui para o mentoring, os cursos de reciclagem retrocedem diante da popularidade do desenvolvimento profissional; enfim, a abordagem contratual negociada entre parceiros substitui as decisões autoritárias (WOODS et al, 1997 apud THURLER, 2008, p. 98)

Esse modelo de relação profissional e tecnológica seria ideal para alcançarmos uma Educação de qualidade, já que a escola passaria a contribuir mais significativamente para a formação de uma sociedade reflexiva e atuante. Todavia, os professores enfrentam muitas dificuldades para lidar com classes cada vez mais heterogêneas e formadas por contextos excessivamente diferenciados, tanto em nível social quanto cultural. Em consequência disso, somente os cursos de capacitação 
não serão suficientes para levar a Educação a um novo patamar, visto que a complexidade e a diversidade das experiências exigem respostas ousadas e corajosas, além de uma nova postura diante das diferenças.

Diante desse fato, compreendemos a necessidade de mudanças ainda nos currículos das universidades para que esses profissionais saiam instrumentalizados e capazes de agir corretamente diante das dificuldades que vão encontrar, porque o professor precisa estar preparado para utilizar estratégias de ensino e aprendizagem coerentes com a experiência de cada escola, e não entender tal realidade como um "pacote" pré-estabelecido. É necessário haver uma reflexão crítica a respeito da formação do professor, da realidade em que cada escola está inserida e do aluno que faz parte dessa escola. Nesse cenário:

a grande maioria dos professores deverá, durante os próximos anos, esforçar-se para desenvolver as competências e perspectivas exigidas pelos reformadores e, muitas vezes, desaprender práticas e crenças relativas aos alunos e às práticas de ensino-aprendizagem que dominaram grande parte de suas carreiras profissionais (HARGREAVES e EVANS, 1997 apud THURLER, 2008, p. 98)

Mudar implica colocar no campo da ação, e não ficar apenas na teoria. Segundo Santos (2002, p. 49), a presença das TIC na escola:

[...] pode representar um movimento ímpar, uma vez que nos permite pensar na redução das distâncias, numa maior integração das escolas entre si e com o mundo contemporâneo; não somente como consumidoras, mas como possibilidades de produzir conhecimento e de fazer de cada espaço escolar um lugar de produção coletiva, no qual sejam constituídas intera- ções não-lineares e onde sejam fortalecidas essas redes de relações.

Novos desafios são apresentados ao professor, mas eles vêm acompanhados de muitas possibilidades. Kenski (2003, p.90) nos diz que:

O professor, em um mundo em rede, é incansável pesquisador. Um profissional que se reinventa a cada dia, que aceita os desafios e a imprevisibilidade da época para se aprimorar cada vez mais. Que procura conhecer-se para definir seus caminhos, a cada instante. Em um momento social em que não existem regras definidas de atuação, cabe ao professor o exame crítico de si mesmo, procurando orientar seus procedimentos de acordo com seus interesses e anseios de aperfeiçoamento e melhoria de desempenho. A estratégia, portanto, deve ser a da reorganização institucional dos sistemas de ensino fundamental que leve ao fortalecimento da organização escolar [...] deslocando para esta última a responsabilidade pelos resultados da aprendizagem de seus alunos.

A dinâmica empregada nas escolas mais inovadoras pressupõe a troca entre os saberes dos professores, o desenvolvimento coletivo e a socialização dos saberes construídos. A inovação reflete no aprendizado individual e contribui para a ampliação dos conhecimentos e das práticas pedagógicas. Finalmente, é importante modernizar a escola com competência, responsabilidade e engajamento, integrar os saberes que o aluno traz, com as novas tecnologias da Educação e aliar o planejamento interdisciplinar, para que a importância dessa conexão esteja explicita.

É preciso considerar que o sistema formal de ensino já não é o único responsável pela Educação dos alunos. O ensino informal, isto é, tudo o que o educando 
aprende fora da escola, deve ser igualmente considerado. Com essa perspectiva, a escola deixa de ser a detentora do saber; daí surge, na Educação, um novo paradigma, que vem acompanhado de transformações na área tecnológica, cognitiva, social e afetiva. A concepção de tempo e espaço, os ritmos da aprendizagem e o comportamento em relação à escola também mudam.

Para que o professor acompanhe esse novo ritmo, é fundamental expandir seus conhecimentos a respeito do que é uma prática pedagógica mediada com o auxílio de ferramentas tecnológicas. Não sendo esse o único aspecto relevante, é necessário capacitá-lo para utilizá-la numa visão crítica, reflexiva e transformadora. A utilização das tecnologias na Educação não pode ser pensada simplesmente como apenas mais uma opção: antes, deve ser considerada um ato educacional responsável e que objetiva a formação integral do ser humano.

Ocorre que, mesmo diante de tanta relevância, muitos profissionais resistem à inserção das novas tecnologias em seu cotidiano, uma rejeição decorrente da própria Educação que receberam. O novo é encarado como desnecessário, já que o "antigo" está sendo validado, e ainda há o medo de ser "substituído" pela tecnologia que, segundo a crença corrente, colabora para cristalizar as antigas práticas pedagógicas. No entanto, o professor jamais perderá sua importância no processo de ensino e aprendizagem. Ele é o mediador entre o conhecimento e a máquina, é aquele que incorpora à situação de aprendizagem a competência que o aluno ainda não tem para que, com a ajuda de mecanismos de mediação semiótica, consiga interiorizar e regular de forma autônoma as novas capacidades (MARCHESI \& MARTÍN, 2003, p. 193).

A formação do professor, seja inicial, seja continuada, depende da qualidade da Educação oferecida, para que ele possa utilizar, de forma crítica, as tecnologias com intencionalidade pedagógica. Porém, as novas tecnologias exigem novas competências. Assim, quanto mais cedo elas forem introduzidas no currículo e na prática pedagógica, maiores serão as chances de sucesso, fundamentalmente no que diz respeito à reformulação dos tempos e espaços da sala de aula, ao papel do professor e ao uso que ele faz das TIC.

Como vimos, o século XXI traz novos paradigmas para a Educação. Ensinar e aprender ganham novas perspectivas e inúmeras ferramentas. Todos são potencialmente competentes para produzir conhecimentos. Mesmo assim, o professor continua tendo um papel indispensável de mediador. Segundo Masetto (2000, p. 144), "mediação pedagógica é a atitude do professor que se coloca como facilitador, incentivador ou motivador [...] uma ponte entre o aprendiz e sua aprendizagem". É o professor quem faz o diagnóstico do aluno, identifica suas habilidades e os conhecimentos que já traz, as competências a serem desenvolvidas, seleciona as mídias, articula os conteúdos, faz a interdisciplinaridade e executa os projetos de mídia-educação.

Cabe ao professor dialogar com diferentes mídias de forma crítica, e não ser apenas um novo espectador, já que o processo educacional deve "dar significado para as teorias e conceitos que o aluno deve aprender e integrar ao seu mundo intelectual" (MASETTO, 2000, p. 148). Esse diálogo oferece novas diretrizes para o processo de ensino e aprendizagem, uma vez que "a textualidade digital [...] muda significativamente a postura e o comportamento do leitor diante dos textos" (SILVA, 2003, p. 124). Portanto, a aprendizagem mediada possibilita um salto de qualidade na Educação, rompe com velhos paradigmas e possibilita novos caminhos através das mídias ou, conforme destaca Hernández (1998, p. 13), as novas tecnologias aplicadas à Educação 
compõem um cenário fundamental:

para soltar a imaginação, a paixão e o risco por explorar novos caminhos que permitam que as escolas deixem de ser formadas por compartimentos fechados, faixas horárias fragmentadas, arquipélagos de docentes e passe a converter-se em uma comunidade de aprendizagem, onde a paixão pelo conhecimento seja a divisa e a educação de meIhores cidadãos o horizonte ao qual se dirige.

Educar com a mídia, pela mídia, para a mídia e entre mídias é o grande desafio para tornar a aprendizagem significativa para os alunos: a utilização da tecnologia da Educação contribui para dar significado à aprendizagem, uma vez que contextualiza 0 processo de ensino e aprendizagem e o aproxima da realidade do aluno. Para Belloni (2001), a Educação para a mídia contribui para "formar um receptor crítico, ativo, inteligente, capaz de se distanciar da mensagem midiática e exercer sobre ela seu poder de análise e crítica". De igual modo, Ausubel (1968 apud MOREIRA, 2001, p. 17) nos diz que aprendizagem significativa é um processo pelo qual uma nova informação se relaciona com um aspecto relevante da estrutura de conhecimento do indivíduo: nesse contexto, as ferramentas de aprendizagem colaborativa auxiliam na consolidação do processo e os projetos de aprendizagem podem viabilizar o uso dessas ferramentas na Educação.

As novas Tecnologias da Informação e da Comunicação convivem harmoniosamente com as outras mídias bem como complementam o currículo formal em atividades individuais ou coletivas, onde os alunos podem: pesquisar, registrar suas memórias, documentar e produzir sentidos para o que se ensina e se aprende. [...] "Resistir e criar. Essas são as possibilidades que nos abre o cotidiano da escola, quando escolhemos agir no fluxo dos acontecimentos" (GALLO 2007, p.39).

Muito embora a maioria dos professores não tenha tido oportunidade de participar de uma formação continuada específica para a implementação das novas tecnologias, elas estão presentes no cotidiano da escola formal ou informalmente. Aproveitar o potencial transdisciplinar das tecnologias para integrar os currículos é, como afirma Gallo, criar novas perspectivas para dar significado ao processo de ensino e aprendizagem.

As tecnologias permitem transformar o real, criar no virtual e estabelecer conexões, produzindo subjetividades. Pois, segundo Oliveira (2005, p.55), para "compreender o cotidiano, cumpre considerar os processos de formação de nossas subjetividades em seus múltiplos espaços/tempos, o potencial que elas incluem, bem como a articulação entre as circunstâncias da situação e nossas possibilidades de ação".

Não podemos negar que o cotidiano da escola já foi invadido pelas novas Tecnologias da Informação e da Comunicação. Castells (2006) diria que se está vivendo em uma sociedade informacional, global e em redes. O conhecimento partiIhado não se esgota, mas multiplica, se transforma e transforma cada sujeito que faz parte desse processo de ensino e aprendizagem.

O grande desafio não é utilizar as tecnologias, mas se apropriar desse conhecimento em um processo colaborativo que permita transformar a realidade.

A Educação precisa ser menos "lecionadora" e mais articuladora de conhecimentos. A Educação empodera os sujeitos e muda a escola, que, como espaço privilegiado, pode fazer a diferença "na" e "para" a vida de milhares de crianças. Nessa perspectiva, o conteúdo que privilegia o compartilhamento de informações e conhecimentos, de forma interdisciplinar e 
colaborativa, tende a ser mais significativo para discentes e docentes.

Presenciamos um novo momento da história onde a sociedade está voltada para a informação e a comunicação. Desta forma, faz-se necessário compreender como as Novas Tecnologias da Informação e da Comunicação (NTIC) integram esse cenário.

\section{REFERÊNCIAS BIBLIOGRÁFICAS}

ALMEIDA, M. E. de. Informática e formação de professores. Brasília: MEC, 2000.

AUSUBEL, D. P. Educational Psychology: a cognitive view. Nova Iorque: Holt, Rinchart and Winston, 1968. Dezembro de 1996. D.O.U. 1996.

BELLONI, M. L. O que é mídia-educação. 2. ed. Campinas (SP): Autores Associados, 2005.

BRASIL. Senado Federal. Constituição: República Federativa do Brasil. Brasília, 1988.

CASTELLS, M. $A$ sociedade em rede. $A$ era da informação: economia, sociedade $e$ cultura. 9. ed. São Paulo: Paz e Terra, 2006.

GADOTTI, Moacir. Perspectivas Atuais da Educação. Porto Alegre: Artes Médicas Sul, 2000.

GALLO, Sílvio. Acontecimento e resistência: educação menor no cotidiano da escola. In: CAMARGO, Ana M. Facciolli de; MARIGUELA, Márcio (orgs.). Cotidiano escolar: emergência e invenção. p.21-39. Piracicaba: Jacintha Editores, 2007

HARGREAVES A.; EVANS, R. (orgs.). Beyond Educational Reform. Buckinghan: Open University, 1997.
HERNÁNDEZ, F. Transgressão e mudança na Educação: os projetos de trabalho. Porto Alegre: Artmed, 1998.

KENSKI, Vani Moreira. Tecnologias e ensino presencial e a distância. Campinas: Papirus, 2003. (Série Prática Pedagógica).

LIBÂNEO, J. C.; OLIVEIRA, J. F.; TOSCHI, M. S. Educação escolar: políticas, estrutura e organização. $10^{a}$ ed., 2012; $5^{a}$ reimpressão, 2014. São Paulo: Cortez, 2012.

LIMA JÚNIOR, Arnaud Soares de. Tecnologias inteligentes e educação: currículo hipertextual. Rio de Janeiro: Quartet; Juazeiro, BA: FUNDESF, 2005.

MARCHESI, A.; MARTÍN, E. Qualidade do ensino em tempos de mudança. Porto Alegre: Artemed, 2003.

MASETTO, M. T. Mediação pedagógica e o uso da tecnologia. In: MORAN, J. M. (org.). Novas tecnologias e mediação pedagógica. 9 ed. (2005). Campinas (SP): Papirus, 2000. P. 133-73.

MORAN, J. M. A Educação que desejamos - novos desafios e como chegar lá. $5^{a}$ ed. 2012; $3^{a}$ reimpressão. Campinas, SP: Papirus, 2013.

MOREIRA, M. A. Aprendizagem significativa: a teoria de David Ausubel. 2. ed. São Paulo: Centauro, 2006.

OLIVEIRA, Inês Barbosa de. Currículos Praticados: entre regulação e a emancipação. Rio de Janeiro: DP\&A, 2005.

SACRISTÁN, J. G. O Currículo: uma reflexão sobre a prática. Tradução: Ernani F. de Rosa. 3a edição. Porto Alegre: Artemed, 2000.

SILVA, E. T. Formação do leitor virtual pela escola brasileira: uma navegação por 
mares bravios. SILVA, E. T. (org.). A leitura nos oceanos da internet. São Paulo: Cortez, 2003. P. 115-26.

TEDESCO, Juan Carlos. Educação e novas tecnologias: esperança ou incerteza? Tradução de Claudia Berliner, Silvana Cobucci Leite - São Paulo: Cortez: Buenos Aires: Instituto Internacional de Planeamiento de la Educacion: Brasília: UNESCO, 2004.

VEIGA, C. G. História da Educação. São Paulo: Ática, 2007.

WOODS. P. et al. Restructuring schools, restructuring teachers. Buckinghan: Open University, 1997. 